Document downloaded from:

http://hdl.handle.net/10251/98700

This paper must be cited as:

J. Antonino-Daviu; Riera-Guasp, M.; José Roger-Folch; Molina Palomares, MP. (2006). Validation of a New Method for the Diagnosis of Rotor bar Failures via Wavelet Transformation in Industrial Induction Machines. IEEE Transactions on Industry Applications. 42(4):990-996. doi:10.1109/TIA.2006.876082

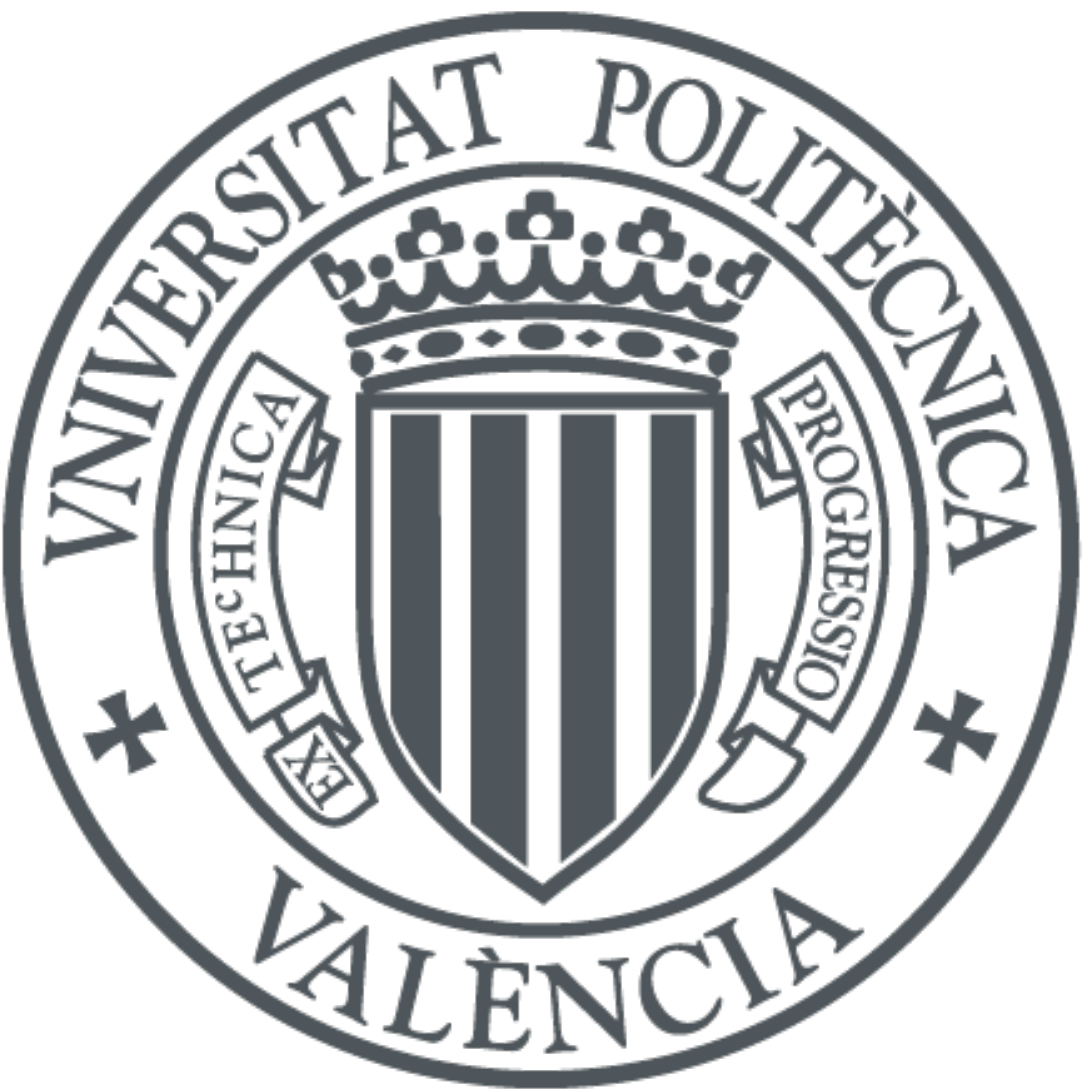

The final publication is available at

http://doi.org/10.1109/TIA.2006.876082

Copyright Institute of Electrical and Electronics Engineers

Additional Information 


\section{Validation of a New Method for the Diagnosis of Rotor Bar Failures via Wavelet Transform in Industrial Induction Machines}

\author{
J. A. Antonino-Daviu* \\ joanda@die.upv.es
}

\author{
M.Riera-Guasp* \\ mriera@die.upv.es \\ J. Roger-Folch* \\ jroger@die.upv.es \\ * Universidad Politécnica de Valencia
Department of Electrical Engineering
P.O.Box 22012
46071 Valencia, Spain \\ Phone: 0034963877592, Fax: 0034963877599
}

\author{
M.P. Molina* \\ pimolina@die.upv.es
}

\begin{abstract}
In this paper, the authors propose a method for the diagnosis of rotor bar failures in induction machines, based on the analysis of the stator current during the startup using the Discrete Wavelet Transform (DWT). Unlike other approaches, the study of the high-order wavelet signals resulting from the decomposition is the core of the proposed method. After an introduction of the physical and mathematical basis of the method, a description of the proposed approach is given; for this purpose, a numerical model of induction machine is used, in such a way that the effects of a bar breakage can clearly be shown, avoiding the influence of other phenomena not related with the fault. Afterwards, the new diagnosis method is validated using a set of commercial induction motors. Several experiments are developed under different machine conditions (healthy machine and machine with different levels of failure) and operating conditions (no load, full-load, pulsating load and fluctuating voltage). In each case, the results are compared with those obtained using the classical approach, based on the analysis of the steady-state current using the Fourier Transform. Finally, the results are discussed and some considerations about the influence of the DWT parameters (type of mother wavelet, order of the mother wavelet, sampling rate or number of levels of the decomposition) over the diagnosis are done.
\end{abstract}

Index Terms - Broken rotor bars, startup transient, fault diagnosis, wavelet analysis.

\section{INTRODUCTION}

The classical approach used in the industrial environment for the detection of broken rotor bars in induction machines is based on the analysis of the stator current in steady-state, using two harmonic components placed around the main frequency component at distances $-2 s f$ and $+2 s f$ (sideband harmonics), where $f$ is the supply frequency and $s$ is the slip [1,2]. This approach has been widely used due to its inherent advantages. However, it has some drawbacks for diagnosis purpose. One of them is load-dependence, since the amplitude of the current components depends on the load connected to the motor and on the inertia of the connected motor-load system. Furthermore, if the machine is unloaded, this approach is unsuitable, because the slip will be approximately zero and the frequencies associated with broken rotor bars will overlap the supply frequency. Another problem of this method is that frequencies similar to those used for rotor bar breakage detection can be generated by other causes such as low frequency oscillating torque loads, voltage fluctuations or bearing faults [3]. Several interesting methods based on steady-state analysis can avoid some of these disadvantages [4-6], but most of them analyse other magnitudes [7-8].

Some new proposals based on the analysis of the current and other magnitudes during the transient processes of the induction machine have been recently published [9-16]. The study of these processes constitutes an important information source that can complement that provided by the steady-state analysis, avoiding its disadvantages but, at the same time, maintaining its simplicity. During those processes the machine works under more critical requirements (currents and stresses), fact that can help to amplify the evidences of certain incipient faults.

In this sense, an approach based on the analysis of the stator current during the startup transient has been recently proposed [9-10]. The proposed approach is based on the application of the Discrete Wavelet Transform (DWT) to the startup stator current in order to extract the evolution of the components associated with the fault during the transient.

Methods proposed by other authors are focused on the analysis of the wavelet coefficients [13,14] or use other mathematical techniques such as the wavelet ridge [15]. Other works [11-12] convolute the startup current signal with a Gaussian wavelet, which was centred on a particular frequency, in order to extract the evolution of the fault components.

Unlike all those methods, the approach proposed by the authors focuses on the study of the high-level wavelet signals resulting from the DWT analysis. This allows a good interpretation of the phenomenon, since the variation of these signals reflects clearly the evolution of the harmonics associated with broken rotor bars during the transient. 
Wavelet theory has proved to be a powerful tool for the analysis of transient processes [17-19]. DWT decomposes the current into a set of signals. Each one of these signals contains the information of the original signal within a certain frequency band. When a broken bar is present in the machine, a characteristic harmonic with a particular frequency variation appears during the startup process. The evolution of this harmonic is reflected clearly in the lowfrequency wavelet signals resulting from the analysis, a fact that allows the detection of this kind of fault in the machine, since this particular variation does not appear in the same machine operating under healthy conditions.

An important advantage of this method is that it gives a correct diagnosis in some cases in which the classical approach does not provide so accurate results, such as the case of voltage fluctuations or oscillating torque loads. In these situations, the steady-state analysis is difficult since some frequency values close to those used for broken bar detection appear in the healthy machine, a fact that can lead to confusion or wrong diagnosis.

Moreover, the use of the wavelet signals (approximation and high-order details) resulting from the DWT constitutes an interesting advantage since these signals act as filters, according to Mallat algorithm, allowing the automatic extraction of the time-evolution of the low frequency components that are present in the signal during the transient. The computation time required for the analysis is usually negligible; in addition, the proposed technique does not use any intricate algorithm for the extraction of the evolution of the signal components.

In this paper, the method for the diagnosis of broken rotor bars is described and applied to industrial induction motors. The new approach is also compared with the wellknown method, based on the Fourier analysis of the stator current in steady-state. Several experiments are developed for different fault cases and operating conditions such as one-bar breakage, two-bar breakages and different load and supply voltage conditions. For testing purposes, the bar breakages were forced in the laboratory in industrial motors in order to compare machine behaviour in healthy and faulty conditions.

\section{PHENOMENON DESCRIPTION AND PROPOSED APPROACH}

As it was shown in [1-4], broken rotor bars cause harmonic components to occur in the stator current. The main of these current harmonics (left sideband component) has a frequency that is given by (1).

$$
f_{L s}=|f \cdot(1-2 s)|
$$

During the startup, the slip $s$ varies from a value equal to 1 at the beginning, to a value near zero in steady-state; thus, if the process is not too fast, the frequency for this harmonic $\left(f_{\mathrm{Ls}}\right)$ changes from the fundamental frequency to zero and again to the fundamental frequency. The existence of this harmonic and this particular evolution was also stated in other works by Watson and others [1112]. The extraction of this harmonic evolution by means of a time-frequency decomposition tool such as the DWT is the basis of the method proposed.

The wavelet theory states that every sampled signal $\boldsymbol{s}$ $\left(\mathrm{s}_{1}, \mathrm{~s}_{2}, \ldots \mathrm{s}_{\mathrm{N}}\right)$ can be approximated by the sum of an approximation signal $a_{\mathrm{n}}$ and some detail signals $d_{\mathrm{j}}$ [17, 20$21]$, according to (2).

$$
s(t)=\sum_{i} \alpha_{i}^{n} \cdot \varphi_{i}^{n}(t)+\sum_{j=1}^{n} \sum_{i} \beta_{i}^{j} \cdot \psi_{i}^{j}(t)=a_{n}+d_{n}+\ldots+d_{1}
$$

Where $\alpha_{i}^{n}, \beta_{i}^{j}$ are the scaling and wavelet coefficients respectively, $\varphi^{n}(\mathbf{t}), \psi^{j}(\mathbf{t})$ are the scaling function at level $n$ and wavelet function at level $j$ respectively, and $n$ is the decomposition level. $a_{n}$ is the approximation signal at level $n$ and $d_{j}$ is the detail signal at level $j$ [20-21].

Mallat algorithm shows that each signal is associated with a certain frequency band. If $f_{\mathrm{s}}$ (samples/s) is the sampling rate used for capturing $\boldsymbol{s}$, then the detail $d_{\mathrm{j}}$ contains the information concerning the signal components whose frequencies are included in the interval $\left[2^{-(j+1)} \cdot f_{s}, 2^{-j} \cdot f_{s}\right] \mathrm{Hz}$. The approximation signal $a_{\mathrm{n}}$ includes the low frequency components of the signal, belonging to the interval $\left[0,2^{-(\mathrm{n}+1)} \cdot f_{s}\right] \mathrm{Hz}[18]$.

Fig. 1 shows the upper-level signals $a 10, d 10$ and $d 9$ resulting from the wavelet decomposition of the startup stator current $(\mathrm{s}(\mathrm{t}))$ in a machine with two broken rotor bars, obtained from simulation with $f_{s}=10,000$ samples/sec. Characteristics of the simulation model are described in [22].The DWT of the startup current was performed using the MATLAB Wavelet Toolbox. Daubechies-40 mother wavelet was used for the analysis. The convenience of using such a high order mother wavelet will be justified in Section IV. It can be seen in the figure that the energies of these wavelet signals, associated with frequency bands below $50 \mathrm{~Hz}$ (supply frequency), show a clear increase in those time intervals when the frequency of the left sideband harmonic is included in the frequency band of the wavelet signal, following a characteristic variation according to the description of the frequency evolution mentioned above.

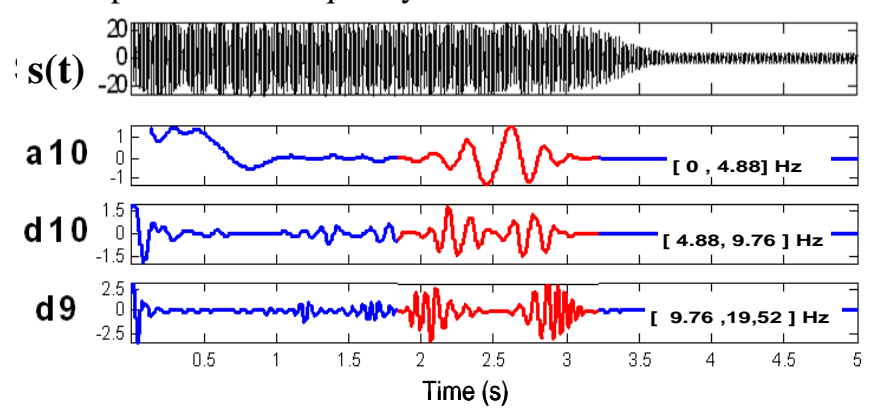

Fig. 1. Characteristic pattern in the wavelet decomposition of the startup current. 
This makes it possible the definition of a general pattern for the characterization of bar breakages [9] based on the decomposition of the startup current, determined by the evolution of the left sideband component frequency. Through analysis of this pattern, a certain influence of the DWT parameters was appreciated. In this sense, the order of the selected mother wavelet was seen to affect the overlapping between the frequency ranges of the different bands. This explains the fact why the pattern is clearer when using a high-order mother wavelet for the analysis.

\section{APPLICATION OF THE NEW METHOD}

Experiments were developed in order to apply the method proposed [9-10] to industrial induction machines. For this purpose a set of $1.1 \mathrm{~kW}$ industrial motors was used. The rotor bar breakages were forced in the laboratory, opening the motors and drilling artificially the holes in the different bars. The main characteristics of the tested motors are: Star connection, rated voltage $\left(\mathrm{U}_{\mathrm{n}}\right): 400 \mathrm{~V}$, rated power $\left(\mathrm{P}_{\mathrm{n}}\right)$ : $1.1 \mathrm{KW}, 2$ pair of poles, primary rated current $\left(\mathrm{I}_{1 \mathrm{n}}\right)$ : 2.7A, rated speed $\left(\mathrm{n}_{\mathrm{n}}\right): 1410 \mathrm{rpm}$ and rated slip $\left(\mathrm{s}_{\mathrm{n}}\right): 0.06$. The number of rotor bars is 28 .

Each tested motor was coupled to its load through a system of pulleys and straps in order to couple both machines through different speed rates. The load is a DC machine with rated speed 2000-3000 rpm, rated voltage $220 \mathrm{~V}, 3 \mathrm{KW}, 1$ pair of poles, excitation rated current: 0.4 A, armature rated current: $13.6 \mathrm{~A}$. The supply frequency used in the experiments was $50 \mathrm{~Hz}$.

Measures of the primary current were taken during the startup transient and in steady-state for the different cases tested. The sampling frequency used for capturing the signals was 5,000 samples/sec. Subsequently, the DWT of the startup current with 8 decomposition levels was performed using the MATLAB Wavelet Toolbox and Daubechies-40 as mother wavelet. Table I shows the frequency bands corresponding to the high-order wavelet signals resulting from the analysis.

Table I. Frequency bands for the high-order signals

\begin{tabular}{|c|c|}
\hline Level & Frequency band \\
\hline$d 7$ & $19.53-39.06 \mathrm{~Hz}$ \\
\hline$d 8$ & $9.76-19.53 \mathrm{~Hz}$ \\
\hline$a 8$ & $0-9.76 \mathrm{~Hz}$ \\
\hline
\end{tabular}

Fourier analysis of the current in steady-state was also performed using MATLAB, with a frequency resolution of $0.2 \mathrm{~Hz}$. Both methods were compared in six different faulty and operating conditions. The cases that are studied are:

\section{A. Healthy machine under full load $(s=0.06)$}

In Fig. 2 (a) and (b) are displayed the DWT of the startup current and the FFT of the steady-state current, respectively. The sideband component with frequency given by (1) does not appear in the Fourier analysis, since there are no broken rotor bars in the machine. The components at $40 \mathrm{~Hz}$ and $60 \mathrm{~Hz}$ are not related with the bar breakage. They are introduced by the pulleys coupling and they are present for the different cases tested.

The wavelet analysis shows that the upper-level signals $(a 8, d 8$ and $d 7)$ associated with frequency bands below 50 $\mathrm{Hz}$, do not present any significant variation, once the electromagnetic transient ends. From this, it can be concluded that the harmonic associated with broken bars is not present in this situation.

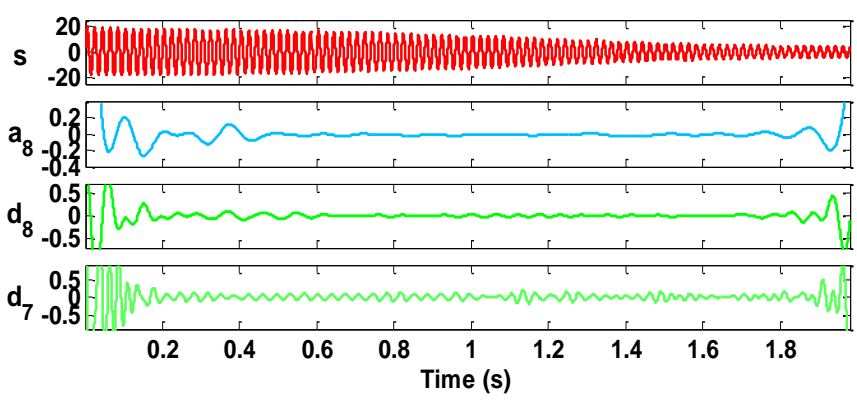

(a)

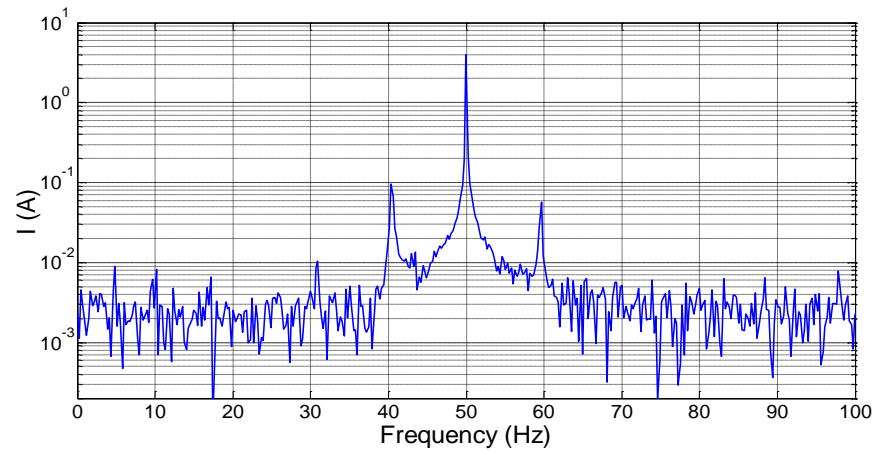

(b)

Fig. 2. Loaded machine in healthy mode. (a) Wavelet analysis of startup current (b) FFT analysis of current in steady state

B. Loaded machine with two broken rotor bars
$(s=0.06)$

Fig. 3 (a) and (b) show the corresponding wavelet and FFT analysis of the current, respectively. The Fourier analysis shows the appearance of two sideband components around the fundamental, a fact that indicates the possible occurrence of a rotor bar breakage in the machine. However, the magnitude of these sideband components is not too high since only two rotor bars are broken.

The analysis of the signals resulting from the wavelet decomposition shows a particular variation that fits the characteristic pattern mentioned before, caused by the presence of broken rotor bars in the machine. From this, it can be concluded that both methods inform about the presence of broken rotor bars in a loaded machine. 


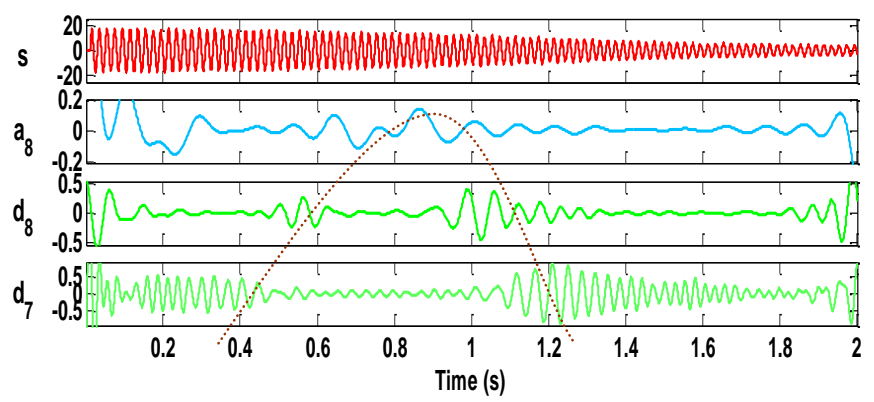

(a)

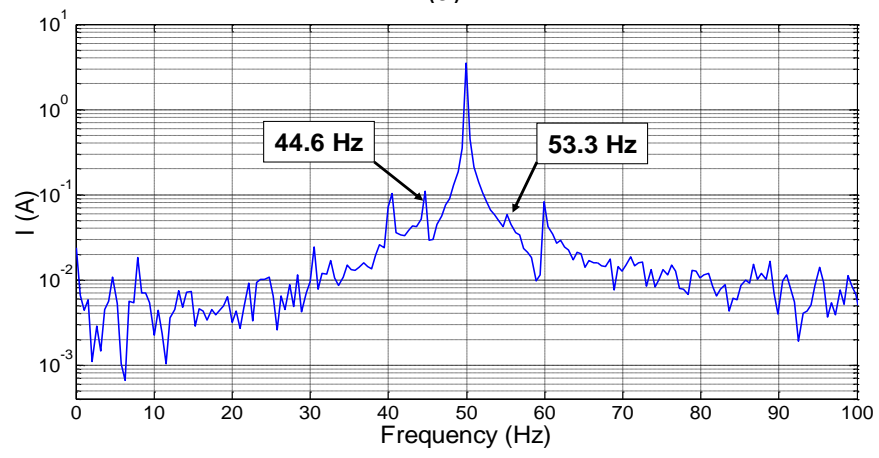

(b)

Fig. 3. Loaded machine with two broken bars. (a) Wavelet analysis of startup current (b) FFT analysis of the current in steady state

\section{Unloaded coupled machine with one broken rotor $\operatorname{bar}(s=0.01)$}

For this experiment, developed with a machine with only one broken bar, the excitation current of the DC machine which acts as load is disconnected, although the motor remains coupled to it. This results in a significant slip reduction. This fact makes diagnosis difficult if only the Fourier method is used, since the sideband components almost overlap with the fundamental frequency [6], as it can be seen in Fig. 4 (b). Nonetheless, the high-order wavelet signals $(a 8, d 8$ and $d 7)$ resulting from the DWT analysis of the startup current show a variation that fits well with the pattern described above. Thus, in this case, the information provided by the method can complement that given by the classical approach in order to reach a more accurate diagnosis.

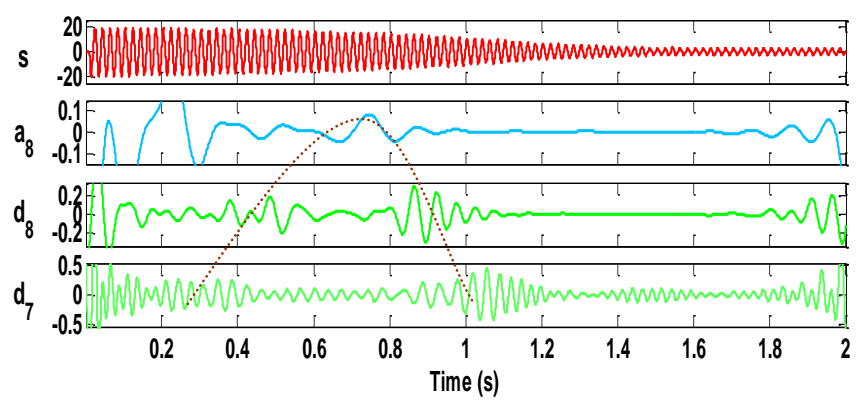

(a)

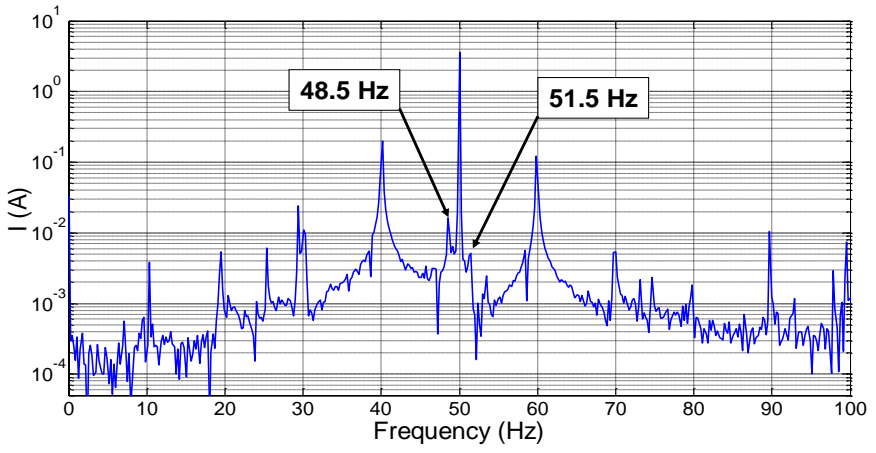

(b)

Fig. 4. Unloaded machine with one broken rotor bar. (a) DWT analysis of the startup current (b) FFT analysis of the current in steady state

D. Unloaded uncoupled machine with one broken rotor bar $(s=0.001)$

For testing this case, the machine is decoupled from the mechanical load and thus, it is only subjected to its own inertia and mechanical losses. In the FFT analysis (Fig. 5 (c)), the sideband components associated with broken rotor bars do not appear. The reason is that the machine is decoupled, the slip is very low and, therefore, the sideband components overlap the frequency of supply. On the other hand, the variations of the wavelet signals in Fig. 5 (a) do not fit with the pattern associated with broken rotor bars mentioned above. This is due to the fact that, since the machine is unloaded, the startup process is too fast and the initial electromagnetic transient overlaps the bar breakage fluctuations. However, this problem can be avoided easily by increasing the duration of this transient, for instance, starting the machine under a reduced voltage. This is what is done in Fig. 5 (b), where the machine is supplied with $88 \mathrm{~V}$. There can be clearly seen those variations that fit with the above described characteristic pattern.

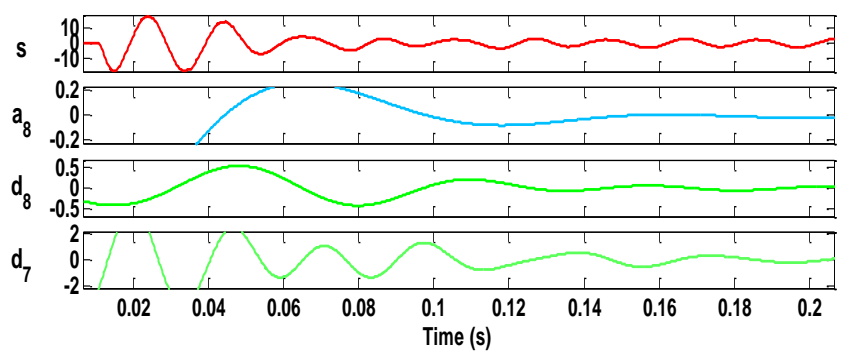

(a)

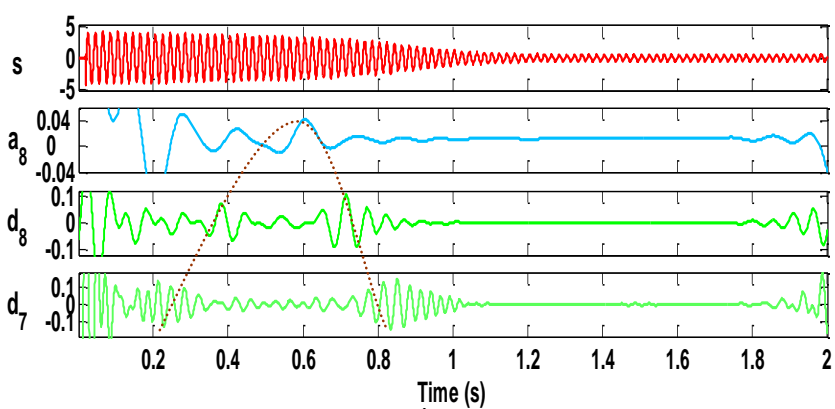

(b) 


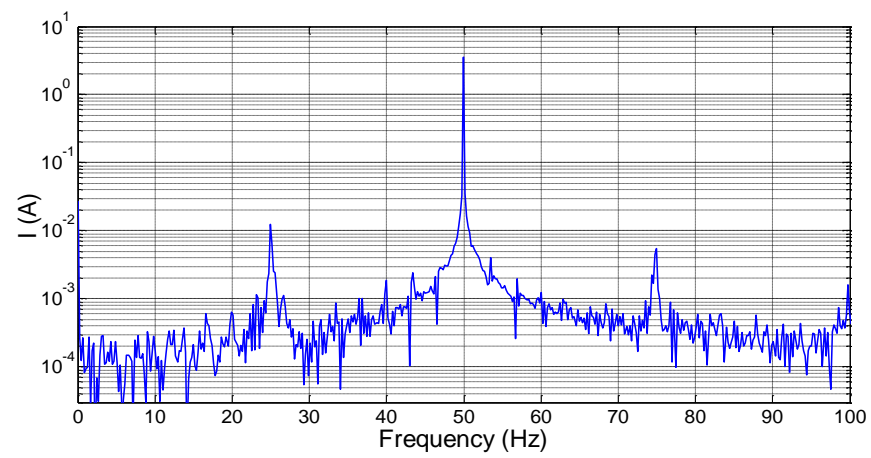

(c)

Fig. 5. Unloaded uncoupled machine with one broken bar. (a) Wavelet analysis of startup current at $390 \mathrm{~V}$ (b) Wavelet analysis of startup current at $88 \mathrm{~V}$ (c) FFT analysis of the current in steady state at $390 \mathrm{~V}$.

\section{E. Healthy machine under full load $(s=0.06)$ with periodical fluctuation in the supply voltage}

In this test, the machine is supplied with a voltage system whose RMS value fluctuates periodically, being the fluctuating frequency $3.3 \mathrm{~Hz}$. This situation can take place in machines supplied by low short-circuit power networks, that feed at the same time, other devices which consume energy in an oscillating way. The fluctuating voltage was obtained by means of a parallel branch which allowed the cyclical connection or disconnection of a suitable resistance in series with each supply phase. This fluctuating supply voltage is shown in Fig. 6.

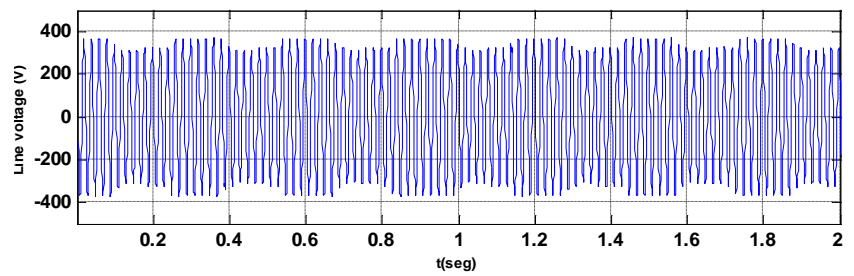

Fig. 6. Fluctuating voltage applied to the machine

The spectrum obtained using the FFT (Fig. 7 (b)) is quite similar to that displayed for the loaded machine with 2 broken rotor bars (Fig. 4 (b)). This analysis could provide a wrong diagnosis of the rotor breakage. On the other hand, the oscillations that can be seen in the signals obtained with the DWT (Fig. 7 (a)) do not fit with the rotor bar breakage pattern. This fact allows discarding the existence of this fault. In this example, it can be seen that the proposed method behaves correctly whereas the Fourier approach can lead to erroneous conclusions.

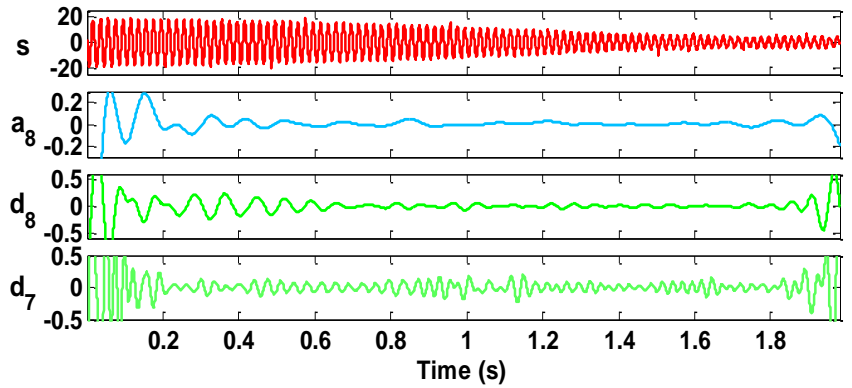

(a)

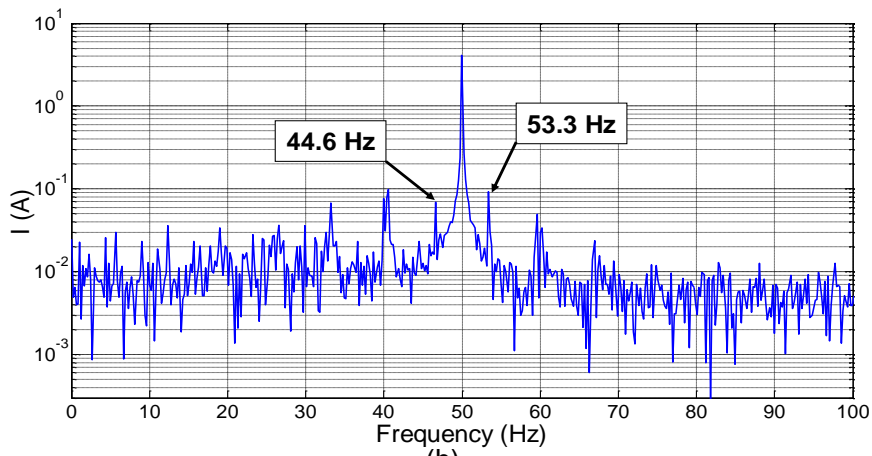

(b)

Fig. 7. Loaded healthy machine with fluctuating voltage.(a) Wavelet analysis of startup current (b) FFT analysis in steady state

\section{F. Healthy machine loaded with low frequency periodical fluctuating torque}

The conditions of this test simulate the operation of a machine coupled through a gear reducer to a load with a cyclically variable torque. During the test, the fluctuating torque is simulated by switching on and off successively the excitation winding of the D.C. machine that acts as load. In the test, the load torque varies cyclically between zero and the rated torque, with a frequency equal to 3.3 Hz. In these conditions, a couple of harmonics appear in the stator current, which frequencies are very similar to those of the left sideband harmonics in a faulty machine [6]. The conclusions of this experiment are similar to those obtained in the previous case. The steady-state analysis, displayed in Fig 8 (b), would lead to a wrong diagnosis of the rotor bar breakage. However, this diagnosis is rejected when analysing the DWT components, which do not show the characteristic pattern corresponding to this fault.

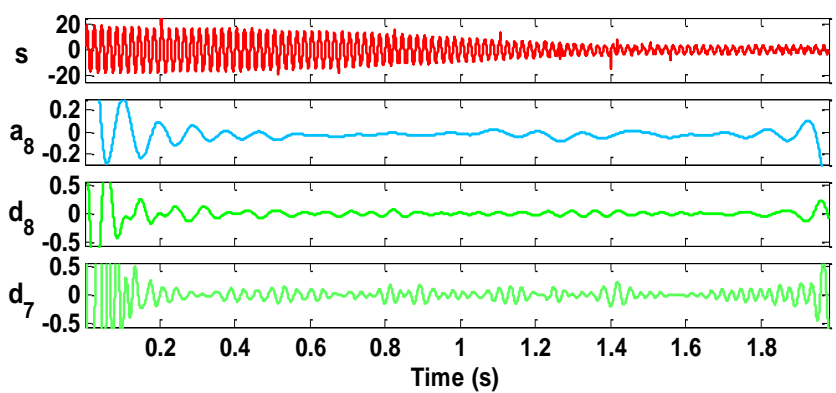

(a) 


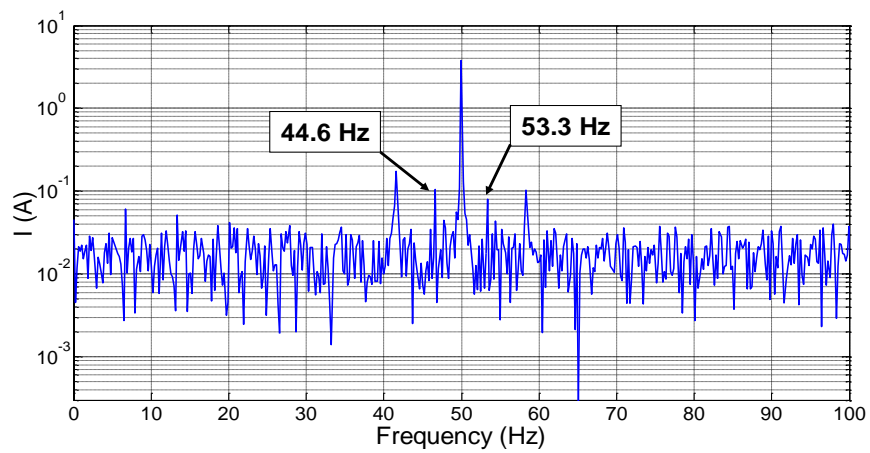

(b)

Fig. 8. Healthy machine loaded with fluctuating torque. (a) wavelet analysis of startup current (b) FFT analysis of current in steady state

\section{SOME CONSIDERATIONS ABOUT THE DWT PARAMETERS}

The different experiments performed showed the suitability of the method for the detection of broken rotor bars. However, some considerations have to be done regarding the different parameters of the DWT decomposition, such as the type of mother wavelet, the order of the mother wavelet or the number of decomposition levels.

With regard to the type of mother wavelet, the Daubechies family was well suited for the application of this method, due to its inherent properties, although other families (simlet, biorthogonal, Gaussian, and specially dmeyer) also allowed a clear detection of the pattern.

When using the Daubechies family, an important fact observed was the overlapping between the frequency bands associated with successive wavelet signals resulting from the DWT of the current. This is due to the fact that the wavelet signals act as non-ideal filters, extracting the components of the signal included within a certain frequency band that can overlap partially with the adjacent band $[17,23]$. In this sense, it was observed that, when using a high-order Daubechies wavelet for signal decomposition, the overlapping was smaller than when using a low-order one. In other words, high-order wavelets behave as more ideal filters, a fact that helps to avoid partially the overlapping between frequency bands.

Finally, the number of decomposition levels $\left(n_{d}\right)$ is related to the sampling frequency of the signal being analysed $\left(f_{s}\right)$. This parameter has to be chosen in such a way that the DWT supplies at least three high-level signals (two details and an approximation) with frequency bands below the supply frequency $f$; this condition implies:

$$
n_{d} \geq n_{f}+2
$$

being $n_{f}$ the level of the detail which contains the supply frequency, that can be calculated using (4).

$$
2^{-\left(n_{d}+1\right)} \cdot f_{s}<f
$$

This condition means that the lower limit of the frequency band of the $n_{f}$ level detail is lower than the supply frequency (see section II).

Thus:

$$
n_{d}>\frac{\log \left(f_{s} / f\right)}{\log (2)}+1 \quad \text { (integer) }
$$

\section{PRACTICAL DISCUSSION ABOUT THE APPLICATION OF THE METHOD}

The application of the method requires a minimum length for the startup, since several periods in each wavelet signal are needed in order to identify the characteristic pattern associated with the bar breakage; as a guideline, with starting times above 0,5 seconds the method is suitable, but it is difficult to be applied if the startup is faster. In comparison with Fourier analysis, the method does not require loading the machine, but its application needs a minimum inertia factor in the group, so that the starting time is as the above commented. This fact is not an important drawback, since machines with low starting time (and consequently, with low inertia factor and light resistant torque) have low risk to suffer from bar breakages.

With regards to the application of the method to machines supplied by electronic controllers, the approach works perfectly when a soft-started is used, since the starting time increases (and this produces a clearer pattern); in addition, the current harmonics produced by the soft-starter have mainly orders that are multiple of the supply frequency and, in consequence, they have no influence on the high order (low frequency) signals used for the diagnosis.

The method, in the way explained here, is not directly applicable to motors supplied by inverters, in the way explained here; in that case the startup is performed with variable frequency and the slip maintains low values along the whole process; so, the evolution of the left sideband harmonic is completely different from that described in Section II, and its frequency remains always close to the fundamental frequency.

In any case, as for the low inertia drives before commented, these cases have a relative interest, since motors driven by inverters or soft-starters usually are subjected to light thermal and mechanical stresses during startup, and thus, have low probability of suffering bar breakages. 


\section{CONCLUSIONS}

This paper introduces a method for the diagnosis of bar breakages in induction machines: In the case of bar breakage, the higher level components of the DWT of the startup stator current follow a characteristic pattern which is described in detail and physically assessed. The method is tested in different faulty and operating conditions and its results are compared with those obtained from the classical Fourier analysis of the stator current in steady-state. In addition, some considerations about the influence of the DWT parameters are done in the paper.

The tests show that if the startup transient is not very short, the reliability of the proposed method for the diagnosis of bar breakages is similar to that of the classical approach, based on the Fourier transform, in the case of loaded motors; but in addition, the method can detect faults in an unloaded condition and it allows a correct diagnosis of a healthy machine in some particular cases where Fourier analysis leads to an incorrect fault diagnosis.

\section{REFERENCES}

[1] G.B Kliman, J Stein, and R.D. Endicott, "Noninvasive Detection of Broken Rotor Bars in Operating Induction Motors," IEEE Transactions on Energy Conversion, vol. 3, no. 4, pp. 873-879, December 1988.

[2] W. Deleroi, "Squirrel cage motor with broken bar in the rotor Physical phenomena and their experimental assessment," in Proc. of ICEM'82. Budapest, Hungary, 1982, pp. 767-770.

[3] M.F. Cabanas, M.G. Melero, and G.A. Capolino, "A new methodology for applying the FFT to induction machine on-line diagnosis," in Proceedings of the International Symposium on Diagnostics for Electrical Machines, Power Electronics and Drives (SDEMPED'99), Gijon (Spain), September 1999, pp. 537-543.

[4] A. Bellini, F. Filippetti, G. Franceschini, C. Tassoni, and G.B. Kliman, "Quantitative evaluation of induction motor broken bars by means of electrical signature analysis," IEEE Transactions on Industry Applications, vol. 37, no. 5, pp. 1248-1255, September/October 2001.

[5] F. Filippetti, G. Franceschini, C. Tassoni, and P. Vas, "AI techniques in induction machines diagnosis including the speed ripple effect," IEEE Transactions on Industry Applications, vol. 34, no. 1, pp 98108, January/february 1998.

[6] R.R. Schoen and T.G. Habetler. "Evaluation and Implementation of a System to Eliminate Arbitrary Load Effects in Current-Based Monitoring of Induction Machines," IEEE Transactions on Industry Applications, vol. 33, no. 6, pp. 1571-1577, November/December 1997.

[7] J.F Watson, K.S Gow, and W.T. Thomson, "Non-invasive instrumentation for on-line management and monitoring of electrical plant," in Proc. Inst. Elect. Life Manage. Power Plants, 1994, pp. 48-56.

[8] M. Negrea , P. Jover, and A. Arkkio, "A comparative investigation on the reliability and accuracy of different diagnostic media when attempting to identify specific faults in an induction motor," Symposium on Power Electronics, Electrical Drives, Automation and Motion 2004 - SPEEDAM 2004 Capri, Italy, 16-18 May 2004, pp. 809- 814

[9] M. Riera, J. Antonino, J. Roger-Folch, and M.P. Molina, "Detection of Broken Rotor Bars in Induction Machines through the Study of the Startup Transient via Wavelet Decomposition," Proceedings of the $9^{\text {th }}$ International Conference on Optimization of Electrical and
Electronic Equipments OPTIM 2004, Brasov, Romania, May 20-21, 2004, pp. 39-46.

[10] J. Roger-Folch, J. Antonino, M. Riera, and M.P. Molina, "A New Method for the Diagnosis of Rotor Bar Failures in Induction Machines via Wavelet Decomposition," in Proceedings of the $9^{\text {th }}$ International Conference on Electrical Machines ICEM 2004, Cracow, Poland, September 5-8, 2004.

[11] R. Burnett, J.F. Watson, and S. Elder, "The application of modern signal processing techniques to rotor fault detection and location within three phase induction motors," European Signal Processing Journal, vol. 49, pp. 426-431, 1996.

[12] J.F. Watson and N.C. Paterson, "Improved techniques for rotor fault detection in three-phase induction motors", in Proc of the 1998 IEEE Industry Applications Conference, 1998. Thirty-Third IAS Annual Meeting., vol. 1, 12-15 Oct 1998, pp. 271-277.

[13] H. Douglas, P.Pillay, and A.K. Ziarani, "A new algorithm for transient motor current signature analysis using wavelets," IEEE Transactions on Ind. Applns., vol. 40, no. 5, pp. 1361-68, Sept./Oct. 2004

[14] H. Douglas, P. Pillay, and A. Ziarani , "Broken rotor bar detection in induction machines with transient operating speeds," IEEE Transactions on Energy Conversion, vol. 20, no. 1, pp. 135-141, March 2005.

[15] Z. Zhang and Z. Ren, "A novel detection method of motor broken rotor bars based on wavelet ridge," IEEE Transactions on Energy Conversion, vol. 18, no. 3, pp. 417-423, September 2003.

[16] J. Milimonfared, H. Meshgin Kelk, S. Nandi, A. Der Minassians, and H. A. Toliyat, "A novel approach for broken-rotor-bar detection in cage induction motors," IEEE Transactions on Industry Applications, vol. 35, no 5, pp. 1000-1006, September/October 1999.

[17] C.S. Burrus, R.A. Gopinath and H. Guo, Introduction to Wavelets and Wavelet Transforms. A primer, Prentice Hall, 1998.

[18] R.Polikar, 'The wavelet tutorial' http://engineering.rowan.edu/ polikar/WAVELETS/WTtutorial.htm $l$

[19] W.S. Chow and S. Hai, "Induction machine fault diagnostic analysis with wavelet technique," IEEE Transactions on Industrial Electronics, vol. 51 no. 3, pp. 558- 565, June 2004.

[20] T. K. Sarkar, M. Salazar-Palma, and M.C. Wicks, Wavelet Applications in Engineering Electromagnetics, Artech House, 2002.

[21] J. S. Walker, A Primer on Wavelets and their Scientific Applications, Chapman \& Hall/CRC, 1999.

[22] M.Riera, "Study of the field harmonics influence on the induction machine behaviour using the space phasors theory," $\mathrm{PhD}$ thesis, Universidad Politécnica de Valencia, 1987.

[23] T. Tarasiuk, "Hybrid wavelet-Fourier Spectrum Analysis," IEEE Transactions on Power Delivery, vol. 19, no. 3, pp. 957-964, July 2004.

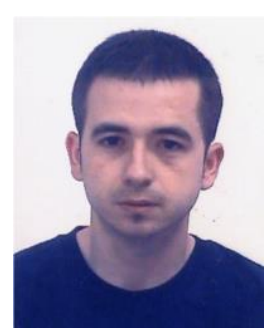

Jose. A. Antonino-Daviu received the M.Sc. degree in Electrical Engineering from the Polytechnic University of Valencia in 2000 . He worked in the private sector, being involved in several international projects. Currently, he is Assistant Professor in the School of Industrial Engineering of the mentioned University, where he develops his docent and research work. $\mathrm{He}$ is currently pursuing the phD degree. His primary research interests are condition monitoring of electric machine, wavelet theory and its application to fault diagnosis and design and optimization of electrical installations and systems. 


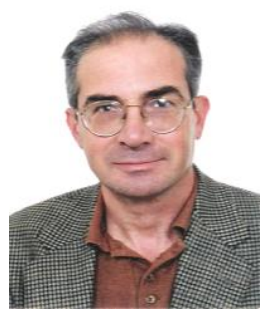

M. Riera-Guasp received the M.Sc. degree in Industrial Engineering and the Ph.D. degree in Electrical Engineering from the Polytechnic University of Valencia (Spain) in 1981 and 1987, respectively. Currently he is an Associate Professor in the Department of Electrical Engineering of the Polytechnic University of Valencia. His research interests include condition monitoring of electrical machines, applications of the Wavelet Theory to electrical engineering and efficiency in electric power applications.

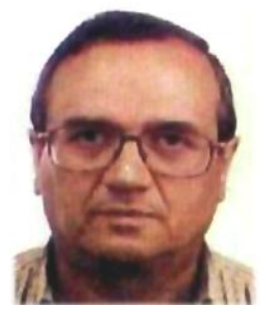

José Roger Folch obtained his M.Sc. degree in Electrical Engineering in 1970 from the Polytechnic University of Cataluña and his Ph.D in 1980 from the Polytechnic University of Valencia, Spain. From 1971 to 1978 he worked in the Electrical Industry as Project Engineer. Since 1978, he joined the Polytechnic University of Valencia and he is currently Professor of Electrical Installations and Machines. His main research areas are the Numerical Methods (F.E.M. and others) applied to the Design and Maintenance of Electrical Machines and Equipments.

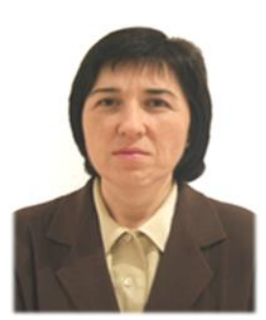

M $^{\text {a }}$ Pilar Molina Palomares received the M.S. degree in Electrical Engineering from the School of Industrial Engineering of the Polytechnic University of Valencia in 1990. She was Assistant Professor from 1993 to 1998. Since 1998, she is Associate Professor in the Department of Electrical Engineering of that University. Her research interests are wavelets and wavelet transform applications to fault diagnosis in transformers and electric motors. 